\title{
INFLUENCE OF ASSEMBLY PROCESS CONDITION OF A GANTRY CRANE ON THE CORROSION RESISTANCE OF WELDS
}

\author{
Krzysztof Staniszewski ${ }^{1}$, Santina Topolska ${ }^{2}$, Aleksander Gwiazda ${ }^{3}$ \\ ${ }^{1}$ Research Network Łukasiewicz - Welding Institute (Instytut Spawalnictwa), \\ Błogosławionego Czesława 16-18, 44-100 Gliwice, Poland \\ ${ }^{2}$ Silesian University of Technology, Faculty of Mechanical Engineering, Department of Welding, \\ Konarskiego 18A, 44-100 Gliwice, Poland \\ ${ }^{3}$ Silesian University of Technology, Faculty of Mechanical Engineering, Department of Engineering Processes Automation \\ and Integrated Manufacturing Systems, Konarskiego 18A, 44-100 Gliwice, Poland \\ Corresponding author: Santina Topolska, santina.topolska@polsl.pl
}

\begin{abstract}
The article presents an analysis of the manufacturing process of gantry crane elements in the unit production regime. Gantry cranes are one of the most important heavy-duty mechanical components designed for lifting and loading heavy and bulky loads. In the analyzed case, the assembly of large-size elements in the form of a welding process was carried out outside. Therefore, there was a problem with the corrosion resistance of the elements produced in this way. In this article, special attention is paid to the performance of welded joints of such large elements and their disadvantages related to the conditions of the assembly process. These joints were made on the basis of typical, low-carbon structural steel (grade S355J2, steel with the number 1.0562) and Nickel alloy (Alloy 59, X2CrNiMoCuN22-5-3, steel with the number 2.4605) using the metal electrode. The weldability of investigated joints was assessed. The aim of the article is to analyze the influence of assembly conditions and subsequent corrosion protection of joints on their corrosion resistance under operating conditions. Appropriate tests have been carried out for this purpose. The tests showed the negative influence of external conditions on the corrosion resistance of the entire gantry crane structure.
\end{abstract}

Key words: crane gantry, assembly, alloy 59, welding technology, corrosion.

\section{INTRODUCTION}

Gantry cranes are the type of cranes used indoors and outdoors, but most often outside of production halls. Due to their design and the way they are made, gantry cranes can be assembled using all technological processes and at the same time in all weather conditions. The device, which a gantry crane is, could be used in industrial plants of various industries. It application allows for efficient loading of vehicles, material handling, as well as handling loads in the processing process.

Due to the versatility of the gantry crane assembly, it becomes important to determine their corrosion resistance when the assembly process was performed outside. This type of assembly takes place when the crane components are so large that their assembly in the room is significantly difficult (Figure 1) or when it must be adapted to the configuration of the client's workplace.

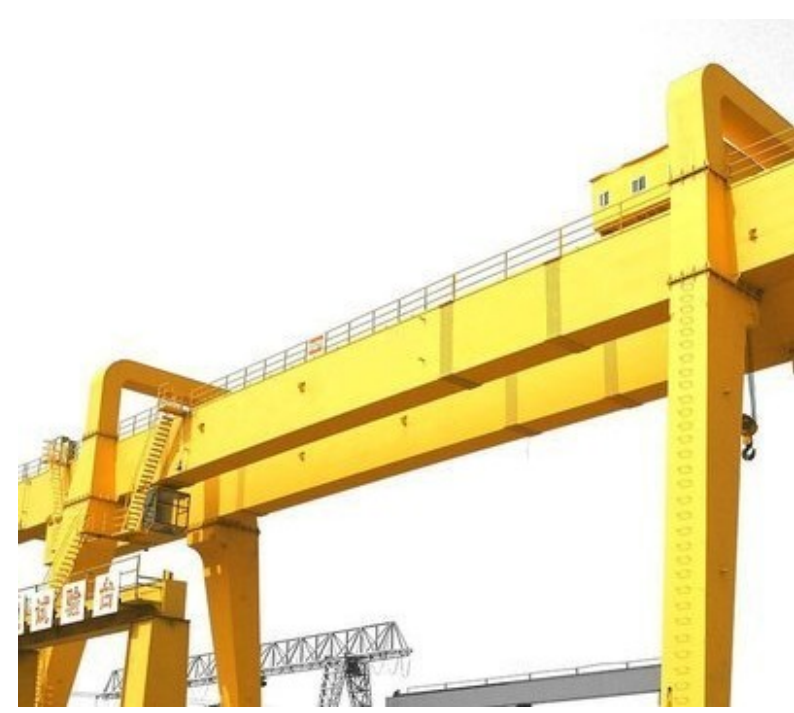

Fig. 1. Example of a large gantry crane (https://www.pioneercranes.co.in/goliath-cranes.html)

However, under certain conditions, it turns out that the assembly of such structures in external conditions leads to the subsequent appearance of defects in structures with a corrosive base (Depale, Bennebach 2019). This type of a case is presented in this study.

\section{MATERIALS AND METHODS}

The manufacturer of gantry cranes assembled this type of solution and covered it with varnish coatings in order to protect the structure against corrosion. It 
was realized due to the dimensions of the gantry crane on the plant site. Corrosion protection was performed in accordance with ISO 8501 (Preparation of steel substrates before application of paints and related products - Visual assessment of surface cleanliness) and ISO 12944 (Paints and varnishes Corrosion protection of steel structures by protective paint systems).

However, the audit found that there are corrosion defects. First of all, the occurrence of spattering was found (Figure 2). Hence, it should be concluded that the paint does not adhere to the substrate, which suggests the wrong nature of the surface in the areas of the joints. Coating thickness measurements (according to ISO 2808 standard) were also carried out using a contact micrometer thickness gauge. These measurements showed large deviations from the intended coating thickness (up to $200 \mu \mathrm{m}$ ). The smallest tested coating thickness is below $50 \mu \mathrm{m}$ and the largest is over $1000 \mu \mathrm{m}$. Exemplary measurements gave the following results (in $\mu \mathrm{m}$ ): $133.2 ; 271.5 ; 460.5 ; 1186 ; 516 ; 846 ; 255.5 ; 471$; $47.5 ; 401.5 ; 376 ; 239.5$ with the required coating thickness of $250 \mu \mathrm{m}$.
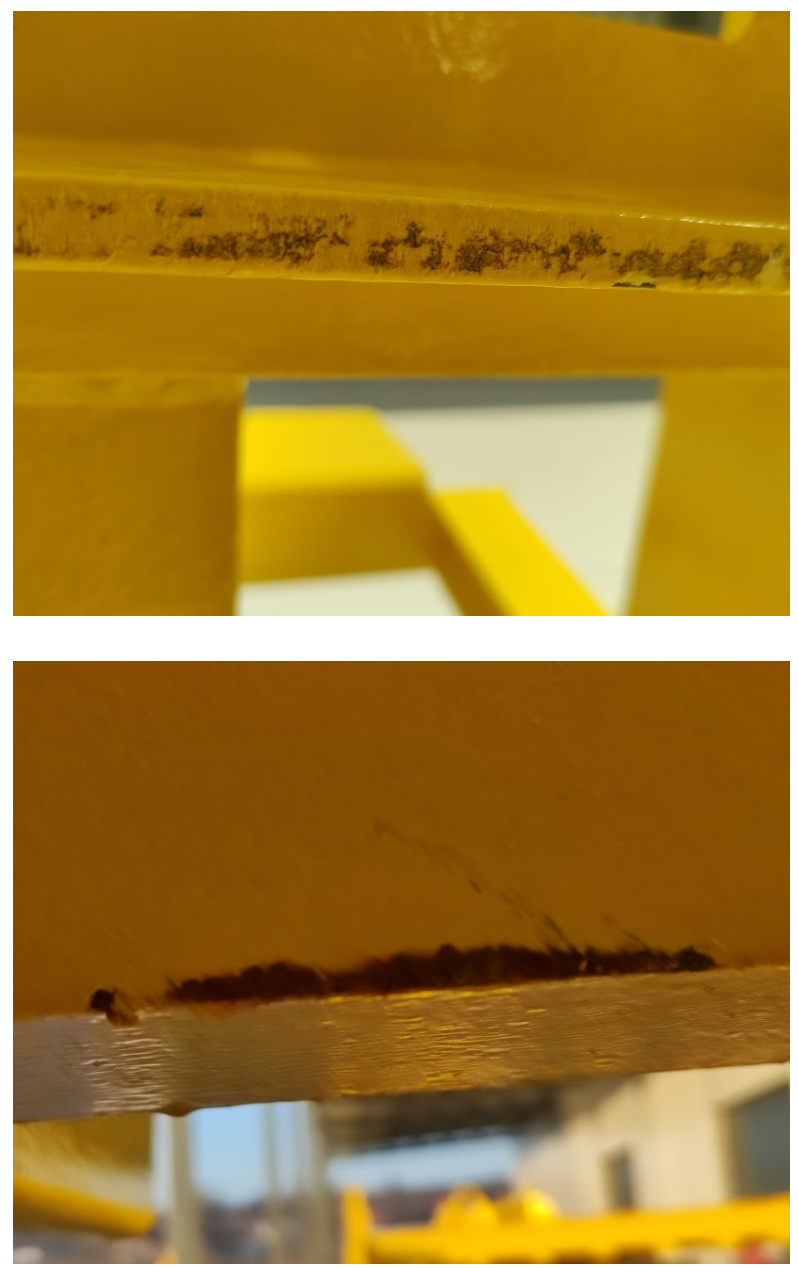

Fig. 2. Spattering occurring in the place of a weld (own elaboration)
The aforementioned situation resulted in undertaking research into the mechanism of corrosion formation in the area of welded joints.

The crane structure was made of typical, low-carbon structural steel (grade S355J2 steel with the number 1.0562 ), while some additional elements were made of Nickel alloy (Alloy 59 - X2CrNiMoCuN22-5-3 steel with the number 2.4605).

Alloy 59 has been applied because of its good mechanical and corrosion characteristics. Alloy 59 (number 2.4605, EN symbol: $\mathrm{NiCr} 23 \mathrm{Mo} 16 \mathrm{Al}$ ) is a nickel-chromium-molybdenum alloy with high mechanical strength and excellent corrosion resistance ((Heubner, 1998; McCoy et al., 2008). According to American system it belongs to the $\mathrm{C}$ family of alloys (Alloy 59 is C-21). This alloy was designed by a Germany company (VDM Metals) for hydrofluoric acid production after a field test in a rotary kiln. Alloy 59 gave superior performance to alloy 686, alloy C-2000, and alloy C-22 (Wessel, 2004). In its group of alloys this one has the highest content of $\mathrm{Cr}$ and Mo. It has also one of the highest content of Ni. At the same time it has the lowest $\mathrm{Fe}$ content. The balance of Ni-Cr-Mo is responsible for its high thermal stability (Wessel, 2004; Karlsson et al., 2008).

One should say that this alloy characterizes by higher corrosion resistance at $50 \pm 2^{\circ} \mathrm{C}$ compared to $22 \pm 2^{\circ} \mathrm{C}$. Moreover it is corrosion resistant even under influence of combination of difficult environment parameters: high temperatures, chlorination and low $\mathrm{pH}$. It is suggested that this resistance is related with the evaporation of dissolved oxygen from $3.5 \% \mathrm{NaCl}$ solution at $50 \pm 2^{\circ} \mathrm{C}$ (Alar et al., 2013). Alloy 59 has a very high corrosion resistance in salt water environment as well (Martin, et al., 2004).

\section{WELDING TECHNOLOGY}

The welding process was conducted using the MIG method (131). The shielding gas was according ISO 14175: I3. The heat input varies between 0.59 up to $1.06 \mathrm{~kJ} / \mathrm{mm}$ for the first joint and between 0.44 up to $1.33 \mathrm{~kJ} / \mathrm{mm}$ for the second one. The measured interpass temperature was $170^{\circ} \mathrm{C}$. For the welding procedure the metal wire S:Ni6059 according EN ISO 18247 was applied. In Figure 3 is presented the sequence of the passes that were made during welding of the analyzed joint. The speed of welding varies between 4.1 and $5.0 \mathrm{~mm} / \mathrm{s}$. The welding current was $155 \mathrm{~A}$ for passes 1 and 2 and $171 \mathrm{~A}$ for the pass No 3 . The voltage of the arc was $28 \mathrm{~V}$. The wire feed speed varies between 9.3 (for passes 1 and 2 ) and 10.2 for the pass 3 . 


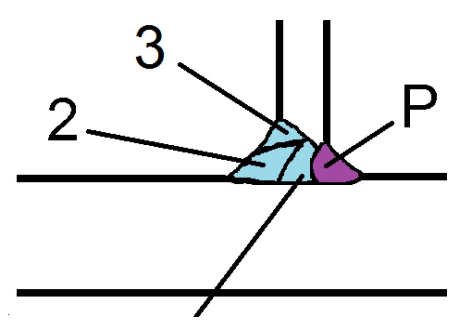

Fig. 3. Specimen no 2 (own elaboration)

1-first pass, 2-second pass, 3-third pass, P- counter pass

\section{MATERIALS AND METHODS}

For testing, two specimens of welding joints of metal sheets with filled welds have been prepared. The base of the joint was made of Alloy 59 and the cross-piece was made of the S355J2 structural steel. The chemical composition of the Alloy 59, according to delivery specification, is presented in Table 1 .

Table 1. Chemical composition of Alloy 59 (\%) according specifications and testing, (own elaboration)

\begin{tabular}{|c|c|c|c|c|c|c|}
\hline & $\begin{array}{c}\mathbf{C} \\
{[\%]}\end{array}$ & $\begin{array}{c}\mathbf{C r} \\
{[\%]}\end{array}$ & $\begin{array}{c}\mathbf{N i} \\
{[\%]}\end{array}$ & $\begin{array}{c}\mathbf{P} \\
{[\%]}\end{array}$ & $\begin{array}{c}\mathbf{M n} \\
{[\%]}\end{array}$ & $\begin{array}{c}\mathbf{S} \\
{[\%]}\end{array}$ \\
\hline Alloy 59 & 0.004 & 22.7 & 60.3 & 0.005 & 0.2 & 0.002 \\
\hline & $\begin{array}{c}\mathbf{S i} \\
{[\%]}\end{array}$ & $\begin{array}{c}\mathbf{M o} \\
{[\%]}\end{array}$ & $\begin{array}{c}\mathbf{F e} \\
{[\%]}\end{array}$ & $\begin{array}{c}\mathbf{C o} \\
{[\%]}\end{array}$ & $\begin{array}{c}\mathbf{A l} \\
{[\%]}\end{array}$ & $\begin{array}{c}\mathbf{C u} \\
{[\%]}\end{array}$ \\
\hline Alloy 59 & 0.03 & 15.4 & 0.8 & 0.01 & 0.2 & 0.01 \\
\hline
\end{tabular}

From the two prepared welding joints two specimens have been cut (one from each joint). The joints were welded as an unilateral filled weld with small, onepass counter weld. The counter weld was made because thermal stresses caused skewing of elements. The cut specimens are presented in Figure 4 and 5. In the figures it is also presented the enlargement of the weld.

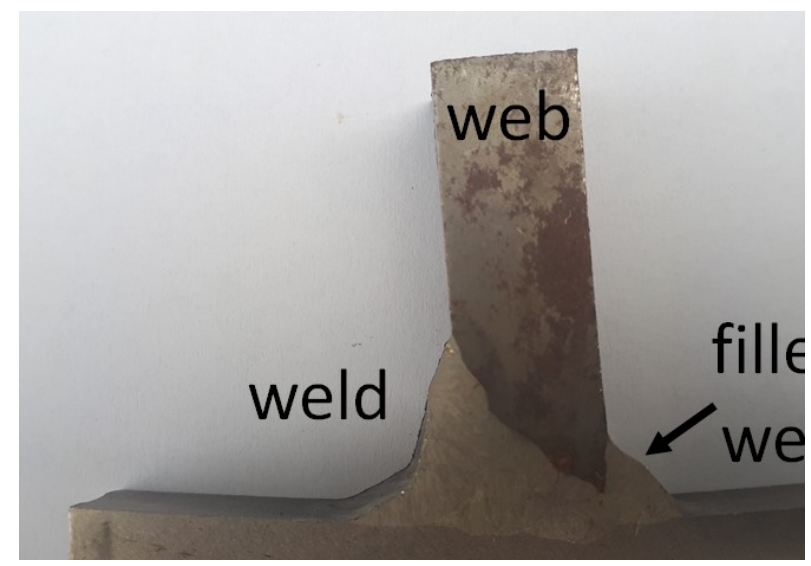

(a)

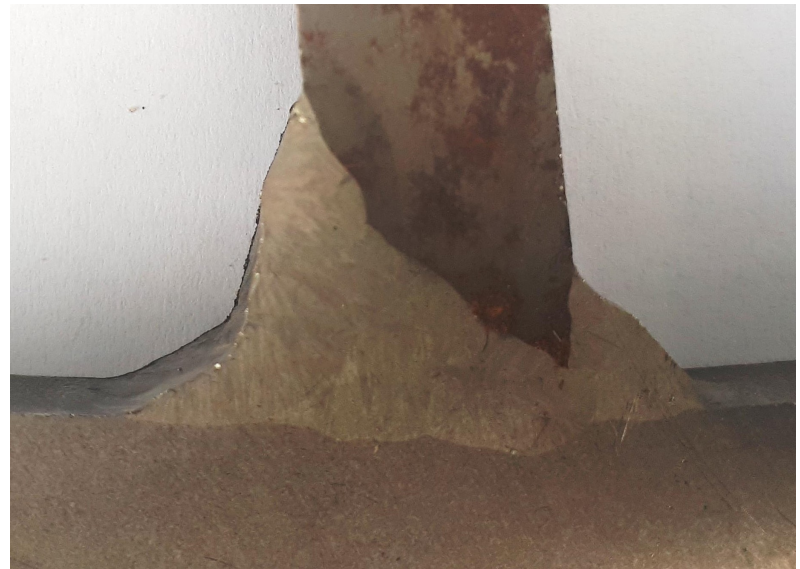

(b)

Fig. 4. Specimen no 1 (own elaboration)

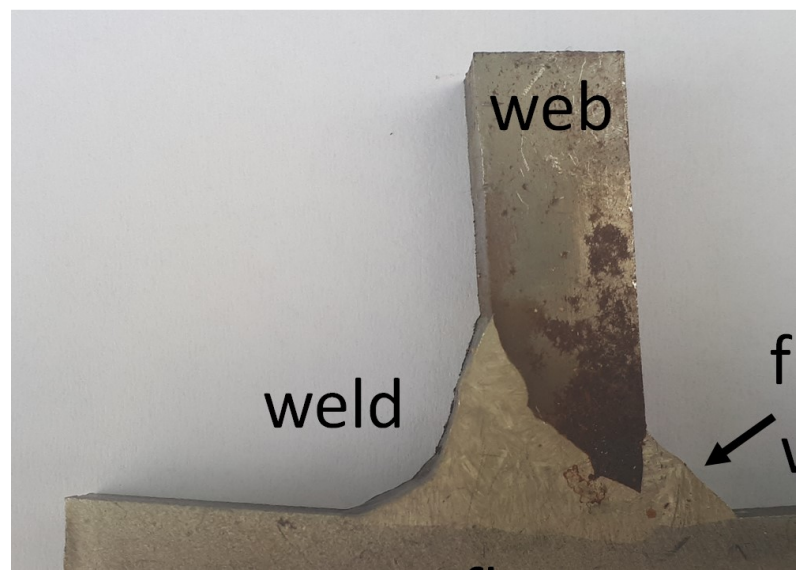

(a)

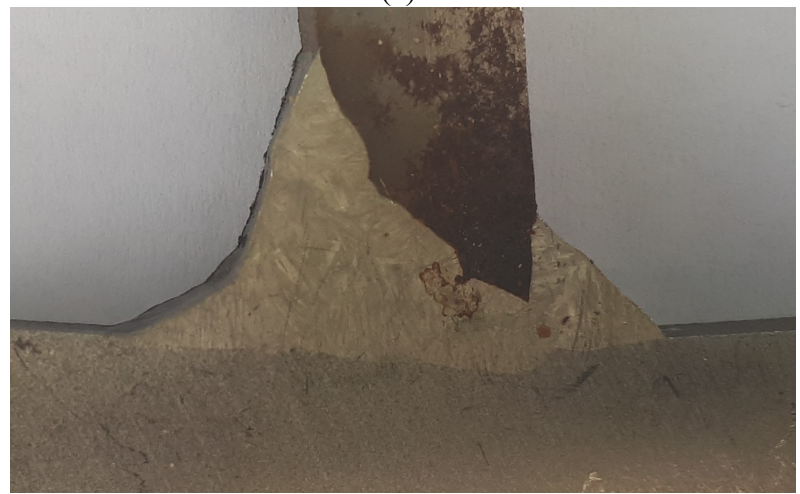

(b)

Fig. 5. Specimen no 2 (own elaboration)

The tested mechanical properties of Alloy 59 gave the values: $R_{e} 0.2$ varies between 415 and $432 \mathrm{MPa}$, $\mathrm{R}_{\mathrm{m}}$ varies between 818 and $839 \mathrm{MPa}$. Tests showed that properties are compliant with the standard. The prepared specimens have then been grinded and polishe. Next they were etched in the solution of Inconel. The macroscopic test was done according to PN-EN ISO 17639 A-E-1.2. Below, in Figure 6 is presented the macroscopic images of the specimens after etching and testing. Penetrant testing according PN-EN ISO 3452-4 showed no visible faults of 
obtained welds. The BDR-L preparation was used as the penetrant.

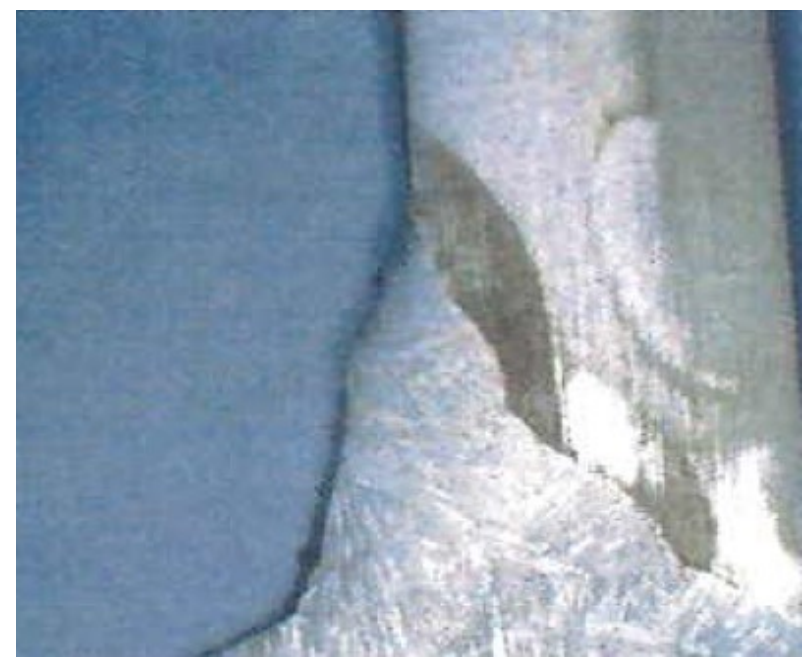

Fig. 6. Macroscopic image of a specimen (own elaboration)

Within the tests it has been also analyzed the average value of hardness. For each area 3 measures have been done. The obtained, average values are presented in Table 2.

Table 2. Average hardness values from 3 measures (HV10), (own elaboration)

\begin{tabular}{|c|c|c|c|c|}
\hline $\begin{array}{c}\text { Base } \\
\text { material } \\
\text { S355J2 }\end{array}$ & $\begin{array}{c}\text { HAZ } \\
\text { S355J2 }\end{array}$ & $\begin{array}{c}\text { Weld } \\
\text { zone }\end{array}$ & $\begin{array}{c}\text { HAZ } \\
\text { Alloy 59 }\end{array}$ & $\begin{array}{c}\text { Base } \\
\text { material } \\
\text { Alloy 59 }\end{array}$ \\
\hline 165.7 & 219.2 & 234.2 & 268.3 & 250.7 \\
\hline
\end{tabular}

On the basis of macroscopic and mechanical properties tests, it is possible to analyze the corrosion issues in the area of welded joints. For this purpose, microscopic examinations were performed.

\section{RESULTS AND DISCUSSIONS}

Next, microscopic examinations were performed. For this purpose, the PHILIPS XL scanning electron microscope was used. The results of these studies allowed us to draw several conclusions. Generally one can state that welding process causes a change in same parameters of Alloy 59. Firstly it should be mentioned the change of its chemical composition. It was observed the segregation of chromium and molybdenum, hence the PREN number of Alloy 59 is high, at the level of 47. Secondly it was observed the change of its microstructure. Austenite changes into dendritic structure. In Figure 7 is presented the microstructure of HAZ - Heat Affected Zone of one of the specimens being under consideration.

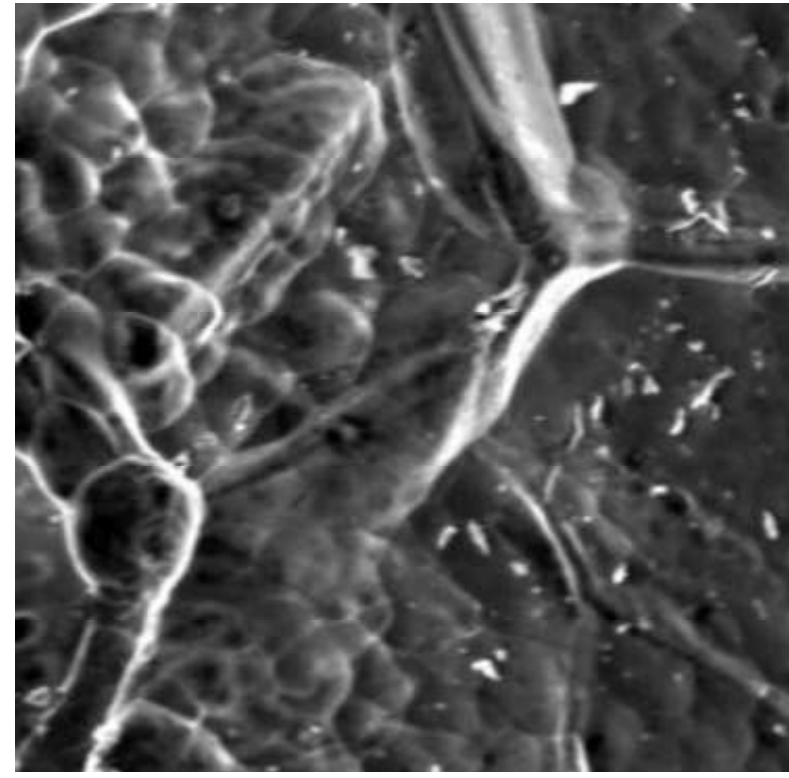

Fig. 7. The HAZ zone of the specimen - mag. 2500

(own elaboration)

The analysis of corrosion behavior of Alloy 59 welding joints allow stating that the specimens of different elements of joints (base material, HAZ, welded zone), at the side of the Alloy 59, spontaneously passivated. It is one of the corrosion resistance mechanisms of this alloy. But generally the worst corrosion resistance characterizes the weld zone or the HAZ zone of heterogeneous element. The weld zone is presented in Figure 8.

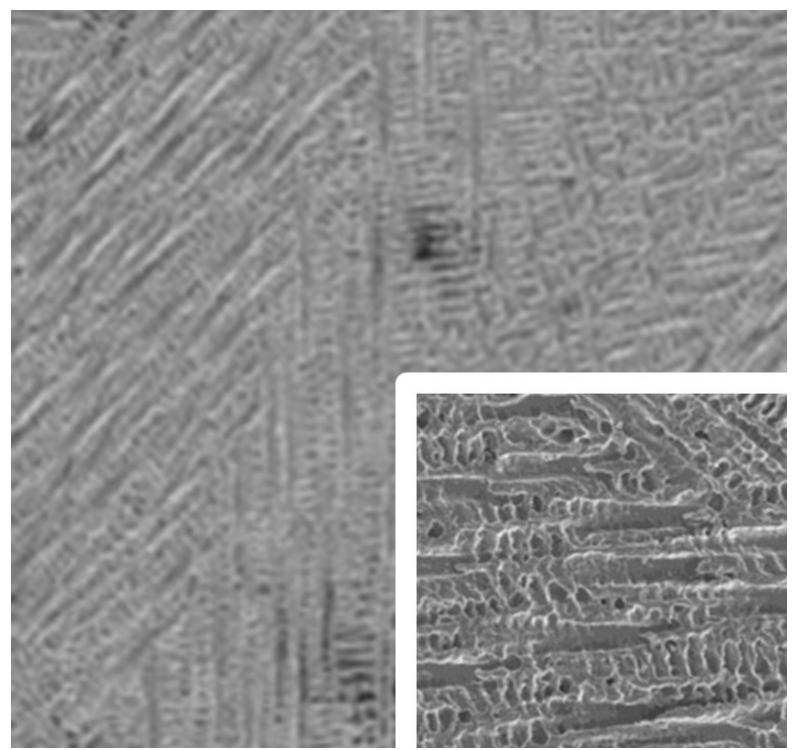

Fig. 8. The weld zone of the specimen - mag. 200/1000 (own elaboration)

The weak corrosion resistance in the weld zone and heterogeneous HAZ is related with the fact that during microstructure changings at welding process the micro galvanic cell is formed. The weld zone converts into anode and base material converts into 
cathode. But because the passivation processes this phenomenon is not severe at the side of the Alloy 59 side. It is more severe on the side of the S355J2 steel side. This process is responsible as the mechanism of the corrosion being observed. The described process was additionally enhanced by careless painting process. In Figure 9 is presented the painting coating of the welded joint of the type being considered in the present study.

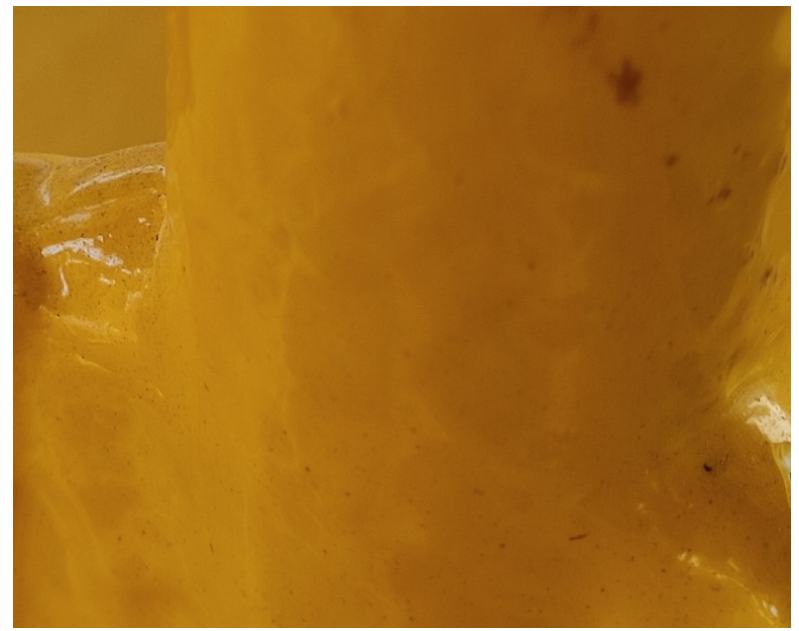

Fig. 9. Painted welded joint (own elaboration)

In order to analyze the quality of the paint coating, a cross-hatch test according to ISO 2409 was carried out for three different places, situated in the vicinity of welded joints. Tests confirmed the lack of paint adhesion to the steel substrate. The incision site was selected such that the coating was not thinner than $150 \mu \mathrm{m}$ but not thicker than $500 \mu \mathrm{m}$. Figure 10 shows one of the test sites.

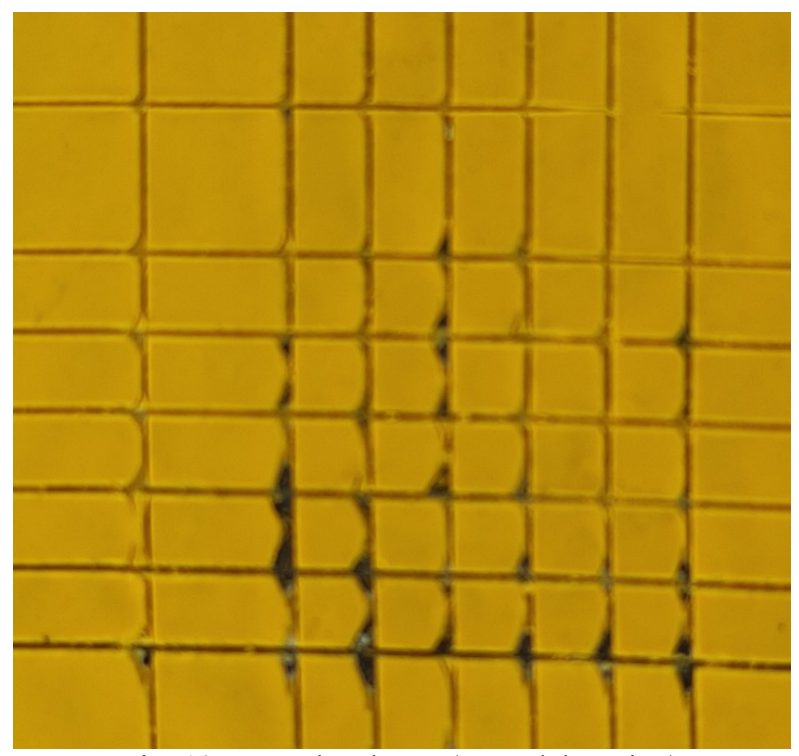

Fig. 10. Cross-hatch test (own elaboration)

Based on these tests, it was found that the exfoliation of the coating can even be classified as classification 2 (i.e. the damage is not greater than 15\%). Only one of the three cuts can be classified as class 1. This means that the paint coating had a certain percentage of a firmly made surface, which to some extent enhanced the corrosion caused by the formation of the micro-cell.

\section{CONCLUSIONS}

The presented research is the first stage of industrial research aimed at developing a welding technology for dissimilar welded joints based on structural steel and Alloy 59. Their aim is to develop the principles of creating an installation structure for chemical industry plants with high mechanical and chemical resistance parameters, and on the other hand with reduced construction costs. One of the tested elements was to increase the temperature between passes to $170^{\circ} \mathrm{C}$, which allowed accelerating the production time of welded elements by about $17 \%$. This also should decrease the conditions which favor the segregation of elements. The second approach to improve the situation is to consider changing the welding technology.

The analyzed welds, made of Alloy 59, using the MIG method, characterized with the corrosion rate (year period) of the weld made of Alloy 59 equal to $0.03 \mathrm{~mm} /$ year. The result is estimated basing on the testing of three specimens of randomly selected welds in the salt chamber. The sensitivity of welds was improved by the polluted air leading to acid rain.

The results of this part of the research that were carried out indicate high mechanical parameters of the obtained welded joints. Next, much more timeconsuming tests are planned for determining the chemical properties of manufactured welded joints, and in particular for their corrosion resistance. In the case, analysed in the paper, the re-preparation of the surface and painting have proved necessary.

\section{REFERENCES}

1. Alar V., Stojanović I., Židov B., Ivušić F., (2013). Corrosion Resistance of Highly Alloyed Materials in $3.5 \% \mathrm{NaCl}$ Solution at Elevated Temperature, International Journal Electrochemical Science, 8 12476 - 12486.

2. Depale B., Bennebach M. (2019). Residual life of steel structures and equipment: problems and application to cranes, Mechanics \& Industry, 20(8) 1-15.

3. International Journal of Electrochemical Science, 7, $10530-10543$.

4. Heubner U., ed., (1998). Nickel Alloys, Marcel Dekker, Basel.

5. Ibáñez-Ferrándiz M., Blasco-Tamarit E., García- 
García D. M., Garcia-Anton J., Guenbour A., Bakour S., (2010). Effect of Temperature on the Corrosion Resistance of Stainless Steels in Polluted Phosphoric Acid, ECS Transactions, 25(37), 63-82.

6. Karlsson L., Bergquist E.-L., Rigdal S., Thalberg N., (2008). Evaluating hot cracking susceptibility of Ni-base SAW Consumables for Welding of 9\% Ni steel, in: Böllinghaus T., Herold H.,, Cross C. E., Lippold J. C., eds., Hot Cracking Phenomena in Welds II, Springer Verlag, Berlin.

7. McCoy S. A., Shoemaker L. E., Crum J. R., (2008). Corrosion Performance and Fabricability of the New Generation of Highly Corrosion-Resistant Nickel-Chromium-Molybdenum Alloys, Special Metals Corporation, www.specialmetals.com

8. Martin F. J., Grolleau A. M., Yentsch C. S., Phinney D. A., Hogan E. A., Natishan P.M., (2000). Temperature and polarization effects on seawater ennoblement of Alloy 59, 328-337 in: Shifler D. A., Tsuru T., Natishan P.M., Ito S., eds., (2004). Corrosion in Marine and Saltwater Environments II: Proceedings of the International Symposium, The Electrochemical Society, Pennington.

9. Nelson T. W., Lippold J. C., Mills M. J., (1999). Nature and evolution of the fusion boundary in ferritic-austenitic dissimilar weld metals. Part 1: Nucleation and growth, Welding Journal, 78(10), 329-337.

10. Nelson T. W., Lippold J. C., Mills M. J., (2000). Nature and evolution of the fusion boundary in ferritic-austenitic dissimilar weld metals. Part 2. Oncooling transformations, Welding Journal, 79(10), 267-277.

11. Pioneer (https://www.pioneercranes.co.in/goliathcranes.html), accessed on 25 march 2021.

12. Prawoto Y., (2013). Synergy of erosion and galvanic effects of dissimilar steel welding: Field failure analysis case study and laboratory test results, Journal of King Saud University Engineering Sciences, 25(1), 59-64

13. Revie R. W., ed. (2011). Uhlig's Corrosion Handbook, John Wiley \& Sons, Hoboken.

14. Tate S. B., Javernick D. A., Lienert T. J., Liu S. (2016). Laser Weldability of 21Cr-6Ni-9Mn Stainless Steel: Part 2 - Weldability Diagrams, Welding Journal, 95, 409-418.

15. Volpi A., Serra G., (2018). Weld overlay of highly corrosion resistant nickel chromium molybdenum alloys, UNS N06059, on low alloy equipment operating at high temperature, Proceedings of the ASME 2018 Symposium on Elevated Temperature Application of Materials for Fossil, Nuclear, and Petrochemical Industries, ETAM2018, 1-12.

16. Wessel J. K., (2004). The Handbook of Advanced Materials: Enabling New Designs, John Wiley \& Sons, Hoboken.
Received: April 17, 2021 / Accepted: December 20, 2021 / Paper available online: December 25, 2021 (C) International Journal of Modern Manufacturing Technologies 